\title{
VIDEOAULA INTERATIVA COMO MATERIAL POTENCIALMENTE SIGNIFICATIVO NA EDUCAÇÃO A DISTÂNCIA
}

\author{
Rosimere Silva Mogetti, PPGCITED-CaVG-IFSul, rmogetti@gmail.com \\ Fernando Augusto Treptow Brod, PPGCITED-CaVG-IFSul, ftbrod@ gmail.com \\ João Ladislau Barbará Lopes, PPGCITED-CaVG-IFSul, joao.lblopes @ gmail.com
}

\begin{abstract}
Resumo
O trabalho buscou conhecer a percepção dos professores formadores do Departamento de Educação a Distância do Instituto Federal Sul-rio-grandense sobre o uso de videoaulas interativas como recurso de ensino. A pesquisa teve por objetivo geral compreender como estão sendo produzidas as videoaulas e de que maneira estão sendo utilizadas como recurso de ensino. A investigação foi feita por meio de um questionário elaborado com questões abertas e fechadas analisadas por meio da abordagem qualiquantitativa do Discurso do Sujeito Coletivo (DSC) de Lefévre e Lefévre sobre como ensinar através desse recurso e quais os principais obstáculos e dificuldades vivenciados pelos professores. Os professores mostraram-se frágeis diante da falta de capacitação oferecida para esse novo modo de ensinar, assim como apontaram a falta de uma equipe de apoio para seu trabalho, mas não deixaram de sublinhar sua disposição para a atualização dos seus conhecimentos. Os professores formadores, através de seus depoimentos, ofereceram exemplos valiosos trazidos de suas experiências com a Educação a Distância. Exemplos que demonstram o interesse que todos têm em obter alguma forma de interagir com o estudante que está em diversos tempo e lugar.
\end{abstract}

Palavras-chave: Aprendizagem Significativa. H5P. Professor Formador. Videoaula Interativa. Material Didático Interativo.

\section{INTERATIVE VIDEO CLASSROOM AS A POTENTIALLY SIGNIFICANT MATERIAL FOR DISTANCE EDUCATION}

\begin{abstract}
The work sought to understand the perceptions of the teachers of the Distance Education Department of the Federal Institute Sul-rio-grandense regarding the use of interactive video classes as a teaching resource. The general objective of the research was to understand how video classes are being produced and how they are being used as a teaching resource. The investigation was carried out by means of a questionnaire prepared with open and closed questions analyzed through the qualitative and quantitative approach of Lefévre and Lefévre's Collective Subject Discourse (DSC) on how to teach through this resource and what are the main obstacles and difficulties experienced by teachers. Teachers were fragile in view of the lack of training offered for this new way of teaching, as well as pointing out the lack of a support team for their work. But they did not fail to underline their willingness to update their knowledge. The teacher Trainers, through their testimonies, offered valuable examples from their experiences with Distance Education. Examples that demonstrate the interest that everyone has in getting some way to interact with the student who is in different time and place.
\end{abstract}

Keywords: Meaningful learning. H5P. Remote teacher. Interactive Video Class. Interactive Teaching Material. 


\section{Introdução}

Um dos recursos didáticos mais valiosos para significar a forma de ensinar na Educação a Distância é a videoaula, podendo ser, ao mesmo tempo, informativa, lúdica e motivadora da aprendizagem. Ela pode associar, em um mesmo objeto didático, elementos visuais, sonoros e textuais, além de também possibilitar o acesso a outros materiais, na forma interativa, possibilitando que o estudante tome decisões diante dos desafios lançados pelo professor. Contudo, não há dúvidas da importância de identificar os desafios que os professores enfrentam quanto ao planejamento e execução das videoaulas, fomentando reflexão e autoavaliação do trabalho que desenvolvem nas salas de aulas virtuais.

Principia-se, dessa forma, em seguimento, o estímulo à descoberta de novas formas de elaborá-las, para que venham ao encontro da missão mediadora dentro da Educação a Distância. Neste sentido, buscou-se construir uma compreensão sobre a natureza das videoaulas que vêm sendo planejadas e elaboradas durante as disciplinas nos cursos da Educação a Distância do Câmpus Visconde da Graça do Instituto Federal Sul-rio-grandense, situado no município de Pelotas/RS para analisar a percepção dos professores formadores quanto ao uso de videoaulas como recurso de ensino na modalidade de educação profissional a distância, a fim de desenvolver um material potencialmente significativo, fundamentado na teoria da Aprendizagem Significativa de David Paul Ausubel.

\section{A Teoria da Aprendizagem Significativa}

Aprendizagem Significativa é o conceito central da teoria da aprendizagem do psicólogo norte-americano David Paul Ausubel e é a partir desta teoria que o presente estudo se sustenta teoricamente para o desenvolvimento de um Guia Didático para o Professor Formador sobre como produzir videoaulas interativas, a fim de motivar e significar as aprendizagens dos estudantes da educação profissional a distância.

Segundo Moreira (2011), esta teoria focaliza principalmente a aprendizagem cognitiva e propõe explicar os mecanismos internos da mente humana com relação à estrutura do conhecimento, e, consequentemente, do aprendizado. $\mathrm{O}$ autor pontua que, para Ausubel, a aprendizagem significa organização e integração do material na estrutura cognitiva, existindo uma estrutura onde ele se processa.

A aprendizagem, segundo essa teoria, é mais significativa à medida que o novo conteúdo é incorporado às estruturas de conhecimento do estudante. A informação que o estudante já domina é um fator de grande influência em seu novo aprendizado. A partir da relação com seu conhecimento prévio é que o novo conteúdo adquire significado. Nessa forma de aprendizagem, dita mecânica, o estudante decora definições, leis, fórmulas, apenas para a avaliação, mas esquece logo após, pois o conteúdo novo não consegue ligar-se a algo já aprendido.

Há a possibilidade de fazer uma ponte entre aprendizagem significativa e videoaulas interativas, já que estas têm o papel de proporcionar uma interatividade que as diferencia das videoaulas tradicionais, lembrando que, a esse propósito, Pelizzari et al., em seu estudo, argumentam que:

(...) o que é sugerido é a participação ativa do sujeito, sua atividade autoestruturante, o que supõe a participação pessoal do aluno na aquisição de conhecimentos, de maneira que eles não sejam uma repetição ou cópia dos formulados pelo professor ou pelo livro-texto, mas uma reelaboração pessoal (PELIZZARI et al, 2002, p.40). 
A videoaula interativa aparece como um recurso diferenciado e uma maneira de tornar dinâmico um vídeo educacional, pois proporciona uma forma de o estudante interagir com ele. Através das videoaulas interativas o estudante pode "manifestar disposição de relacionar o novo material de maneira substantiva e não arbitrária a sua estrutura cognitiva" (MOREIRA; MASINI, 2001, p.23), sendo esta uma das condições para a ocorrência da aprendizagem significativa, e o professor, ao orientá-lo nesta tarefa, fomentar esta desejada interatividade através do material educacional disponibilizado no Ambiente Virtual de Aprendizagem, com o auxílio das tecnologias.

\section{Caminhos Metodológicos}

Esta pesquisa utiliza os princípios de um estudo de caso, aplicado no Departamento de Educação a Distância, $\mathrm{DEaD} / \mathrm{CaVG}$, onde foi analisada a percepção dos Professores Formadores sobre o uso de videoaulas como recurso de ensino. Buscouse, igualmente, uma reflexão e uma autoavaliação sobre a maneira de ensinar através desse recurso, assim como uma sondagem a respeito dos obstáculos e dificuldades já vivenciadas por eles.

Anota-se, nesse esforço de conceituação do estudo de caso, o que Costa et al. (2013) assentam:

O estudo de caso refere-se a uma análise detalhada de um caso específico, supondo que é possível o conhecimento de um fenômeno a partir do estudo minucioso de um único caso.

Sendo assim, é um método de pesquisa ampla, permitindo-nos aprofundar o conhecimento sobre a temática da pesquisa.

O instrumento utilizado para a coleta de dados foi um questionário aplicado com questões abertas e fechadas. As questões abertas permitiram estimular o entrevistado a expressar-se livremente. Foram feitas quatro questões fechadas sobre o tempo de trabalho na educação a distância, programas em que atuou e as respectivas disciplinas, e, por fim, sobre o número de videoaulas já gravadas. Seguindo-se no propósito de obter o posicionamento de cada um dos professores formadores sobre o tema objeto da pesquisa, acrescentou-se cinco questões abertas.

Os onze sujeitos que participaram da pesquisa, respondendo efetivamente o questionário, foram convidados a assinar um Termo de Consentimento Livre e Esclarecido (Resolução 466/2002) e informados sobre o sigilo e privacidade de seu anonimato.

Em um próximo momento, foi roteirizada e gravada uma videoaula interativa para o Curso de Pedagogia EPT (Educação Profissional e Tecnológica) da UAB (Universidade Aberta do Brasil), sendo que a mesma foi disponibilizada para os estudantes no Ambiente Virtual de Aprendizagem, na disciplina Metodologia e Estratégias de Ensino. A videoaula interativa tratou do tema "Teoria da Aprendizagem Significativa de David Ausubel" e proporcionou aos estudantes de todos os pólos do curso a experiência de participar dela ativamente, através do acesso a links, figuras e exercícios que testavam seu conhecimento e atenção sobre o que estava sendo explanado.

Como desejava-se conhecer o que a coletividade de professores formadores expressa no questionário, escolheu-se como metodologia para a análise dos dados obtidos durante a pesquisa o Discurso do Sujeito Coletivo. 
A técnica consiste basicamente em analisar o material verbal coletado nas entrevistas, sendo que os depoimentos são a matéria-prima. Lefévre e Lefévre, autores que desenvolveram este método, mencionam o que o difere de outros métodos:

O diferencial da metodologia do DSC é que a cada categoria estão associados os conteúdos das opiniões de sentido semelhante presentes em diferentes depoimentos, de modo a formar com tais conteúdos um depoimento síntese, redigido na primeira pessoa do singular, como se tratasse de uma coletividade falando na pessoa de um indivíduo (LEFÉVRE; LEFÈVRE, 2014, p.2).

Realizando a tarefa de definição do método, Lefévre e Lefévre (2005, p.6) dizem: "O Discurso do Sujeito Coletivo é, em suma, uma forma ou expediente destinado a fazer a coletividade falar diretamente".

A proposta basicamente consiste em analisar o material verbal coletado no questionário, extraindo-se de cada um dos depoimentos, as ideias centrais e/ou ancoragens, chegando-se as correspondentes expressões-chaves. Dessa forma, são compostos um ou vários discursos-síntese na primeira pessoa do singular, conforme sublinham os autores.

Os discursos coletivos são construídos por meio de expressões-chaves $(\mathrm{ECH}), \mathrm{o}$ que significa escolher os trechos de texto que dão significado ao discurso, deixando de fora os trechos de conteúdo que não são relevantes. A ancoragem é o alicerce teórico do que poderá ter sido identificado no discurso do sujeito.

\section{Avaliação dos Resultados}

Foi iniciada a análise do questionário sondando-se sobre a experiência dos Professores Formadores através das questões fechadas propostas. Nesse caminho, foi possível concluir que o tempo de atuação na Educação a Distância é de um a dez anos, sendo que nesse interregno os professores formadores gravaram de duas a onze videoaulas para diferentes disciplinas.

Sobre a opinião quanto ao tema de pesquisa, buscada através das questões abertas, importante também anotar-se que emergiram seis discursos coletivos, dois discursos para cada questão aberta apresentada. Na sequência esses discursos são apresentados e analisados em separado, trazendo-se, por vezes, a ancoragem feita pela reflexão de alguns autores. Será exposto um dos discursos na íntegra, para demonstrar como são construídos. Para os demais serão descritas apenas as discussões e os resultados encontrados.

Em resposta à indagação: "Qual o maior desafio que você encontra para produzir uma videoaula?", emergiram os seguintes discursos: "Domínio e Suporte Técnico"; "Videoaula atrativa".

O discurso do sujeito coletivo "Domínio e Suporte Técnico", DSC1, traz a discussão sobre as condições que os professores encontram quando enfrentam o desafio da gravação das videoaulas para as suas disciplinas, evidenciando que eles percebem uma falta de suporte técnico durante a gravação.

\section{DSC1: Domínio e Suporte Técnico}

O maior desafio me parece ser o tempo a ser investido em edição do material. Em princípio, não existe suporte profissional para filmar as aulas. No início admito que não ficaram tão boas, pela falta de recurso tecnológico, experiência, assim como, saber editar o vídeo. Só para ilustrar, tive que convidar alunos meus para me filmar e quando não conseguia, procurava o setor de $\mathrm{EAD}$, que numa ocasião, me disponibilizou uma tutora, que não 


\begin{abstract}
tinha muita noção sobre filmagem. Ela se mexia muito com a câmera e me interrompia durante a filmagem. Tive que repetir várias vezes a videoaula. Inquestionavelmente, falta estrutura para a gravação, também assinalaria a pouca familiaridade com softwares de edição, e, sobretudo, ausência de uma equipe que pudesse se dedicar a esse trabalho. Por exemplo, quando eu fiz minhas videoaulas o programa usado não permitia edição. Caso eu errasse, era necessário recomeçar do zero. Além disso, a questão do domínio da técnica mesmo sobre como agir na frente de uma câmera, muitas vezes não sabemos como nossa "atuação" deve ser melhor realizada para gerar nos alunos interesse pelo assunto. Enfim, o resultado tecnicamente ruim de produções próprias me é desencorajador.
\end{abstract}

Nessa esteira, percebe-se que as perguntas do questionário deixaram os docentes bem à vontade para expressar todas as dificuldades e angústias que encontram quando utilizam esse recurso de ensino; e revelam a insatisfação com a estrutura de apoio oferecida, que até, em muitas ocasiões, inexiste, fato que torna esse desafio desanimador para eles.

Soma-se também a evidência, que os professores formadores estão conscientes que a sua falta de domínio prejudica a sua atuação na hora da gravação de suas videoaulas, assim também na fase posterior de edição do vídeo, tornando o resultado final aquém das expectativas.

A esse propósito, Silva registra que uma das dificuldades mais frequentes do professor ao posicionar-se de forma natural frente às câmeras é a falta de hábito:

\begin{abstract}
O medo da câmera e sua consequentemente inibição é a barreira mais difícil a ser vencida. Poucos ficam à vontade diante daquela lente, que é na verdade o olho do aluno que ninguém vê, que não dá alento, muito menos o feedback tão necessário para saber se a aula está ou não atraindo a atenção, se está sendo ou não motivadora, ou se há compreensão ou dúvidas referentes ao conteúdo (SILVA, 2011, p.4).
\end{abstract}

Nesse discurso, também fica evidenciado que o professor formador tem dificuldade em lidar com a câmera, ficando pouco à vontade em comunicar-se com os estudantes através dela, visto que está acostumado com a interação presencial proporcionada pelo ensino tradicional, e, dessa forma, anseia pelo apoio da equipe para motivar-se.

Inquestionavelmente, nota-se a clara necessidade de uma formação, não só dele, mas de todos envolvidos, para que saibam usar todas as técnicas necessárias, além da conscientização da coordenação sobre a necessidade de disponibilizar a estrutura necessária em todas as fases de construção desse importante recurso de ensino para o ensino a distância.

Importante registrar, nesta altura, que o produto gerado por esta pesquisa oferece aos professores formadores uma alternativa no formato de videoaulas concebidas por eles, disponibilizando um passo a passo para a criação de videoaulas interativas onde o estudante pode participar ativamente, o que vai ao encontro das inquietações percebidas através do questionário aplicado.

O discurso do sujeito coletivo "videoaula atrativa", DSC2, retrata a preocupação dos professores formadores sobre a melhor forma de chamar a atenção dos estudantes para suas videoaulas. Importa ressaltar, que o conteúdo apresentado nas videoaulas deve ser relevante e adequado à estrutura cognitiva do aprendiz. Dessa forma, a videoaula interativa muito tem a colaborar com esse processo, já que com seus elementos interativos possibilitam aos docentes a contextualização ressaltada por eles em seu discurso, o que torna esse material potencialmente significativo.

V. $18 \mathrm{~N}^{\mathrm{o}} 1$, julho, 2020 RENOTE DOI: 
Silva (2011) deixa claro a importância da criatividade e versatilidade em uma videoaula bem produzida, tornando os estudantes mais motivados e interessados. E é nesse sentido que os professores formadores direcionam seu pensamento na conquista da atenção dos estudantes através de um material mais atrativo, sendo que também não deixaram de pontuar a importância da contextualização do conteúdo, o que vem ao encontro do propósito de dar-se sentido e significado ao que se quer ensinar para uma aprendizagem significativa.

Importante o registro de Moreira:

[...]uma das condições para a ocorrência da aprendizagem significativa é que o material a ser aprendido seja relacionável (ou incorporável) à estrutura cognitiva do aprendiz, de maneira não arbitrária e não literal. Um material com essa característica é dito potencialmente significativo (MOREIRA, 2006, p.11).

Importa ressaltar, que o conteúdo apresentado nas videoaulas deve ser relevante e adequado à estrutura cognitiva do aprendiz. Dessa forma, a videoaula interativa muito tem a colaborar com esse processo, já que com seus elementos interativos possibilitam aos docentes a contextualização ressaltada por eles em seu discurso, o que torna esse material potencialmente significativo.

Quanto à questão: "O que você considera necessário para desenvolver uma videoaula?", os professores formadores formaram dois discursos: "Conhecimento do Conteúdo, desenvoltura frente câmera e linguagem adequada "e "Estrutura de apoio e Formação".

O Discurso do Sujeito Coletivo "Conhecimento do Conteúdo, Desenvoltura frente à Câmera e Linguagem Adequada", DSC3, destaca o cuidado que os professores formadores percebem como necessários ao criar e produzir suas videoaulas. Cuidados estes, com propósito de que o estudante receba os conteúdos da forma mais clara e objetiva possível. Sendo assim, segundo os professores formadores pesquisados, amplificam-se as chances de que a videoaula venha efetivamente a prender sua atenção.

Os professores formadores, com muita propriedade, acentuam a importância do conhecimento do conteúdo, não esquecendo da necessidade dos saberes didático pedagógicos para a boa apresentação de uma videoaula.

Para Mill e Silva $(2018$, p.9) o conhecimento pedagógico de conteúdo envolve reflexão sobre a prática docente e é uma discussão essencial: “(...)esta é uma discussão essencial para o entendimento da aprendizagem da docência na $\mathrm{EaD}$, especialmente quando consideramos a incorporação das Tecnologias Digitais de Informação e Comunicação na reflexão".

Considera-se que essa reflexão foi feita pelos professores formadores através da questão formulada, já que acentuaram a contextualização através de exemplos práticos, como forma necessária para o desenvolvimento de uma videoaula.

Por sua vez, o Discurso do Sujeito Coletivo "Estrutura de Apoio e Formação", DSC4, traz o importante destaque à necessidade de uma oferta de capacitação aos professores formadores, para que, dessa forma, tenham em mãos instrumentos para a utilização das técnicas necessárias para criar um roteiro, assim como o auxílio de uma equipe para colocá-lo em prática na hora da gravação.

Não se duvida que os professores formadores, através desse discurso, demostram estar cientes da importância da videoaula para a educação a distância, mas, ao mesmo tempo, clamam novamente por uma estrutura de apoio que os auxilie em todo o processo de criação e execução de uma videoaula, começando por uma capacitação 
que consideram ser a base para que utilizem esse recurso educacional de forma a tornálo mais cativante.

Nesse sentido, vale a anotação de Mill e Silva:

\begin{abstract}
Entre os autores da área é consenso a necessidade de uma boa formação para atuação docente no contexto da Educação a Distância e, consequentemente, a preocupação com a qualidade de ensino a ser executado por estes profissionais. Pode-se dizer que, seja para atuar na educação presencial ou na $\mathrm{EaD}$, a formação do professor não pode se dar por concluída ao findar a graduação, nem se limitar à uma pós-graduação específica (MILL; SILVA, 2018b, p. 5).
\end{abstract}

$\mathrm{Na}$ visão do autor suprastranscrito, é pacífico entre os estudiosos da área que o professor de qualquer modalidade de ensino deve preocupar-se com sua formação durante o decorrer de toda sua carreira profissional, não só durante a permanência nos bancos universitários, para que mantenha seu bom desempenho.

Referindo-se a terceira questão aberta apresentada: "Em sua opinião, como planejar e produzir uma boa videoaula? Por quê?", os professores formadores produziram os discursos a seguir arrolados: "Planejamento e roteiro" e "Facilitar a Aprendizagem".

O DSC5, denominado "Planejamento e Roteiro" demonstra uma preocupação dos professores formadores com o planejamento das videoaulas, destacando-se a importância de uma roteirização, inclusive destacando que a experiência dos sujeitos é que fez com que refletissem sobre essa necessidade.

O Discurso do Sujeito Coletivo denominado "Facilitar a Aprendizagem", DSC6, traz a reflexão dos formadores sobre como deve ser abordado conteúdo em uma videoaula. Através desse discurso, fica evidenciado que os professores formadores conhecem as vantagens de lançar-se mão da videoaula como ferramenta facilitadora da aprendizagem, e, principalmente, que têm a consciência de que tudo ficará armazenado para que o estudante reveja quantas vezes quiser. Assim, destacam a necessidade de uma construção lógica da videoaula, que, dessa forma, deve ser coerente, objetiva, didática, clara, de curta duração e sem repetições.

Além disso, não deixam de pontuar nesse discurso, a importância da oferta de exemplos práticos alicerçados pelo conteúdo, o que mais uma vez se aproxima da valoração de uma aprendizagem significativa, conduzindo o estudante a construção do conhecimento e do pensamento crítico.

Moreira (2010, p.23) não se olvida de nos ofertar valiosos ensinamentos de como os educadores podem auxiliar os estudantes nessa busca por uma aprendizagem significativa. Destaca-se a seguir um desses ensinamentos

\footnotetext{
A facilitação da aprendizagem significativa depende muito mais de uma nova postura docente, de uma nova diretriz escolar, do que de novas metodologias, mesmo as modernas tecnologias de informação e comunicação.
}

Não é demais pontuar-se, igualmente, que a busca por esta nova postura está nas reflexões dos nossos professores formadores pesquisados. Mesmo que alguns ainda não tenham em mente o conceito de aprendizagem significativa, demonstram a consciência de que uma nova postura se faz necessária no caminho docente. $\mathrm{O}$ aprimoramento da construção de uma videoaula deve vir acompanhada, indubitavelmente, dela. 
Em resposta à questão: "Como você percebe a melhor forma de promover interação por meio de videoaulas?", os professores ofereceram dois discursos: "Recursos do AVA e Ferramentas Externas" e "Questionamentos, Tarefas e Desafios".

No discurso que aborda as redes sociais como forma de promover a interação, denominado "Recursos do AVA e Ferramentas Externas", DSC7, os professores formadores demonstram desconhecer os softwares capazes de transformar uma videoaula tradicional em uma videoaula interativa. Esse discurso, torna claro que os formadores consideram que apenas, chats, fóruns, games, webconferência, redes sociais e outras ferramentas externas, possam proporcionar a interatividade no ambiente virtual de aprendizagem. O que nos leva a considerar de grande importância que seja levado ao conhecimento deles, as outras formas existentes, dentro da própria videoaula, capazes de promover essa interação, de forma inovadora, instigante e atrativa aos estudantes, como é o caso da videoaula interativa criada através do H5P.

No discurso, que completa o pensamento dos professores sobre a interação através de videoaulas, denominado "Questionamentos, tarefas e desafios", DSC 8, os professores seguem demonstrando seu desconhecimento expressado no discurso anterior.

Os professores formadores, através de seus depoimentos, ofereceram exemplos valiosos trazidos de suas experiências com a Educação a Distância. Exemplos que demonstram o interesse que todos têm em obter alguma forma de interagir com $o$ estudante que está em diversos tempo e lugar. Suas palavras também demonstram que consideram importante o uso de algum material interativo que os faça "dialogar" e que tentam isso, na medida do conhecimento que conquistaram até o momento.

Behar (2013, p.3) sobre a caminhada docente, dá o seguinte destaque à formação constante do professor: "O seu processo de formação será eterno, uma vez que necessita refletir sobre seus próprios processos".

E é esse caminho indicado nos depoimentos dos professores formadores, evidenciando que estão dispostos e em busca de novos conhecimentos que incentivou nosso estudo sobre como produzir um produto educacional capaz de auxiliar na criação de um outro tipo de videoaula para o trabalho na Educação Profissional a Distância.

Como produto, foi desenvolvido um Guia Didático para orientar o Professor Formador da EaD Profissional, embasado nas sugestões obtidas com os professores formadores e estudantes, sujeitos desta pesquisa, sobre como produzir videoaulas capazes de motivar e significar o ensino na educação profissional a distância, tendo como sustentação a teoria da aprendizagem significativa de David Ausubel.

Para acompanhar o Guia Didático, foi produzida uma videoaula interativa para a disciplina Metodologia e Estratégias de Ensino do Curso de Pedagogia EPT da Universidade Aberta do Brasil (UAB), que ficará disponível no site da Pós-graduação em Ciências e Tecnologias na Educação (PPGCITED) como forma de exemplificar o processo de desenvolvimento desse tipo de videoaula.

A videoaula sobre Aprendizagem Significativa teve sua interatividade produzida através do plugin H5P que é uma estrutura de colaboração de conteúdo gratuita e de código aberto que é o H5P, abreviatura de HTML5 Package, que visa facilitar a criação, partilha e reutilização de conteúdo HTML5 interativo e foi inserida no Ambiente Virtual de Aprendizagem da disciplina.

No Guia Didático é disponibilizado o passo a passo para que o docente possa inserir em suas videoaulas tradicionais vários tipos de elementos interativos, assim como esclarecimentos de como pode ser preparada uma videoaula interativa, ou seja, o guia traz sugestões de como ele pode dar sentido e significado aos conteúdos apresentados. A videoaula interativa, além de ter sido disponibilizada para os 
estudantes, também oferta exemplos para que os docentes tenham conhecimento de como ela pode ser produzida.

Desta forma, os professores terão a possibilidade de criar videoaulas interativas, e os estudantes poderão ter experiências ativas, assim como receber feedbacks instantâneos através da interação que o H5P proporciona.

\section{Considerações Finais}

A videoaula interativa mostra-se como uma ferramenta muito potente de aproximação entre o professor formador e o aprendiz que estuda a distância, proporcionando o despertar de seu afeto, pelo ambiente virtual de aprendizagem, como sublinhamos nos ensinamentos do filósofo Baruch Spinoza, assim como, é capaz de promover um bom encontro entre eles, encontro esse que, embora virtual, pode promover o sentimento de acolhimento necessário.

Interessante, a esse respeito, é o que Novikoff e Cavalcanti $(2015$, p.18) citando Deleuze e Parnet (1998), registram: "um professor pode promover o que para Spinoza é um bom encontro. Um bom encontro com o conhecimento é o caminho para que os discentes sejam afetados ao máximo por paixões alegres".

A pesquisa feita com os professores formadores oferta a clara percepção de que esses atores da educação a distância estão cientes dos problemas enfrentados nesta modalidade de ensino e de que muito ainda precisa ser feito para melhorar.

Os professores mostraram-se frágeis diante da falta de capacitação oferecida para esse novo modo de ensinar, assim como apontaram a falta de uma equipe de apoio para seu trabalho, mas não deixaram de sublinhar sua disposição para a atualização dos seus conhecimentos.

A educação a distância precisa de novas iniciativas, novos rumos, novas propostas e de uma equipe disposta a encontros generosos e cheios de afeto e aprendizagem. Ademais, vale a anotação que, a partir deste trabalho, os professores formadores terão à disposição um guia didático e uma videoaula interativa demonstrativa ${ }^{1}$, que podem auxiliá-los na tarefa de incrementar sua atuação e facilitar uma aprendizagem realmente significativa para o estudante a distância.

\section{Referências Bibliográficas}

BEHAR, Patricia Alejandra; BERNARDI, Maira; MARIA, Sandra Andrea Assumpção. Educação a distância: a construção de competências docentes. Disponível em:<http://www.br-ie.org/pub/index.php/pie/article/view/2590/2246>. Acesso em: 27 mai. 2018.

COSTA, Alexandre de Souza, NASCIMENTO; Aline Vieira do; CRUZ, Emilia Barroso; TERRA, Letícia Labati; SILVA, Marina Ramalho e. O Uso do Método de Estudo de Caso na Ciência da Informação do Brasil. 2013. Disponível em: <http://www.revistas.usp.br/incid/article/view/59101>. Acesso em: 16 out. 2019.

LEFÉVRE, F.; LEFÉVRE, A. M. O Sujeito Coletivo que fala. Disponível em: < http://www.scielo.br/pdf/icse/v10n20/17.pdf>. Acesso em: 13 set. 2018.

\footnotetext{
${ }^{1} \mathrm{O}$ guia didático e a videoaula interativa estão disponíveis em:

< http://ppgcited.cavg.ifsul.edu.br/mestrado/>. Acesso em: 28 nov. de 2019.

V. $18 \mathrm{~N}^{\mathrm{o}} 1$, julho, 2020 RENOTE DOI:
} 
LEFÉVRE, F.; LEFÉVRE, A. M. C. O Discurso do Sujeito Coletivo: Um Novo Enfoque em Pesquisa Qualitativa (Desdobramentos). $2^{\mathrm{a}}$ ed. Caxias do Sul. RS. Educs. 2005.

LEFÉVRE, F.; LEFÉVRE, A. M. C. Discurso do Sujeito Coletivo: Representações Sociais e Intervenções Comunicativas. Disponível em:

<http://www.scielo.br/pdf/tce/v23n2/pt_0104-0707-tce-23-02-00502.pdf〉. Acesso em 28 ago. 2018.

MILL, Daniel; SILVA, Claeton Pedro Ribeiro da. Aprendizagem da Docência para Educação a Distância: Uma Breve Revisão da Literatura sobre Docência Virtual. Disponível em:

<https://www.aunirede.org.br/revista/index.php/emrede/article/view/377>. Acesso em: 16 out. 2019.

MOREIRA, Marco Antonio. O que é afinal Aprendizagem Significativa. Disponível em <http://moreira.if.ufrgs.br/alfinal.pdf>. Acesso em: 25 out. 2018.

MOREIRA, Marco Antonio. A Teoria da Aprendizagem Significativa e sua Implantação em Sala de Aula. Brasília: UnB. 2006.

SILVA, Patricia Rodrigues. A Importância da Capacitação do Professor na Apresentação das Teleaulas e Utilização da Produção Audiovisual em EaD. Disponível em: <http://www.abed.org.br/congresso2011/cd/160.pdf>. Acesso em 29 mai. 2018. 